\title{
Necrotic and apoptotic volume changes of red blood cells investigated by low-angle light scattering technique
}

\author{
Igor V. Mindukshev ${ }^{\text {a }}$, Vladimir V. Krivoshlyk ${ }^{\text {b }}$, Elena E. Ermolaeva ${ }^{c}$, Irina A. Dobrylko ${ }^{\text {a }}$, \\ Evgeniy V. Senchenkov ${ }^{c}$, Nikolay V. Goncharov ${ }^{c}$, Richard O. Jenkins ${ }^{\mathrm{d}, *}$ and \\ Alexander I. Krivchenko ${ }^{\text {a }}$ \\ ${ }^{a}$ I.M. Sechenov Institute of Evolutionary Physiology and Biochemistry, Russian Academy of Sciences, \\ St-Petersburg, Russia \\ ${ }^{\mathrm{b}}$ LUMEX Ltd, St-Petersburg, Russia \\ ${ }^{\mathrm{c}}$ Research Institute of Hygiene, Occupational Pathology and Human Ecology, St-Petersburg, Russia \\ ${ }^{\mathrm{d}}$ School of Allied Health Sciences, De Montfort University, Leicester, UK
}

\begin{abstract}
A low-angle light scattering technique, which has been applied previously to studies of blood platelets and Ehrlich ascite tumor cells, revealed differences in the dynamics of necrotic and apoptotic red blood cell death. Under hypotonic loading or in ammonia medium, red blood cells (RBC) swelled to a critical size (diameter approximately $13 \mu \mathrm{m}$ ) prior to hemolysis (necrosis). Under acidic loading, hemolysis occurred with less pronounced swelling of cells (diameter approximately $10 \mu \mathrm{m}$ ). Apoptosis induced by a calcium ionophore resulted in initial formation of echinocytes, followed by development of rounded red blood cells with uneven membrane, capable of agglomeration. In such a way, RBC aggregation can precede the final stages of the RBC apoptosis when small cellular fragments are generated. On the basis of erythrograms of the cells hemolysing in ammonia medium, the echinocytic (preapoptotic) and stomatocytic (prenecrotic) RBC were discerned due to the very high resistance of apoptotic RBC to osmotic (ammonia) loading.
\end{abstract}

Keywords: Hemolysis, erythrogram, necrosis, apoptosis, swelling, shrinkage

\section{Introduction}

Cellular deformation of red blood cells (RBC) is necessary for their penetration into capillaries of $2 \mu \mathrm{m}$ diameter. The capability of the RBC to change shape (transform) has been shown to be dependent upon interaction of the band 3 membrane protein $\left(\mathrm{Cl}^{-} / \mathrm{OH}^{-}\right.$or $\mathrm{Cl}^{-} / \mathrm{HCO}_{3}^{-}$exchanger through which transport of $\mathrm{CO}_{2}$ takes place) connected with cytoskeleton (together with glycophorin) and the cytoplasmic proteins spectrin, ankyrin and protein 4.1 [1]. Changes in the original shape of RBC (biconcave disk) accompanies various pathological states of these cells (spherocytes, echinocytes, stomatocytes, etc.), and is inevitably connected with disturbance of the transport functions of RBC.

Both apoptosis and necrosis forms of cell death have been observed in RBC. Necrotic death of RBCcommonly known as hemolysis - is the cause of various anemic states amalgamated into a group of

\footnotetext{
${ }^{*}$ Corresponding author: R.O. Jenkins, School of Allied Health Sciences, De Montfort University, Leicester, LE1 9BH, UK. Tel.: +44 116 2506306; E-mail: roj@dmu.ac.uk.
} 
hemolytic anemia [2]. Despite the absence of mitochondria and a nucleus in RBC, typical markers of apoptosis in these cells - cell shrinkage, cell membrane blebbing, and breakdown of phosphatidylserine asymmetry - have been clearly demonstrated by Lang et al. [3-5]. Apoptosis and necrosis are opposing forms of cell death, both in regards to their mechanisms of development and to preceding events. Cell swelling is the predominant sign for cell death by necrosis, while cell shrinkage is the predominant sign for cell death by apoptosis; events termed as necrotic volume increase (NVI) and apoptotic volume decrease (AVD), correspondingly [6]. Mechanisms for cell volume changes differ depending on cell type [7-10]. As distinct from the most other cells, RBC placed in acidic medium undergo a pronounced hemolytic reaction (necrosis). Another way of inducing RBC hemolysis, which is usually applied for separating leukocytes, is by placing blood in isotonic medium containing $\mathrm{NH}_{4}^{+}$in place of $\mathrm{Na}^{+}$[11]. The key mechanism initiating hemolysis has been shown to be the $\mathrm{Cl}^{-} / \mathrm{OH}^{-}$exchanger responding to shifts in the membrane gradient of $\mathrm{pH}$, because DIDS (4,4'-diisothiocyanostilbene-2,2'disulfonic acid disodium salt) - an inhibitor of this exchanger - completely prevents the hemolysis [12]. Both decrease of extracellular $\mathrm{pH}$ (in the case of acidic hemolysis) and increase of intracellular $\mathrm{pH}$ (in ammonia medium) lead to activation of the exchanger and entry of chlorine ions into cells. Concomitantly, sodium ions (through $\mathrm{Na}^{+} / \mathrm{H}^{+}$antiporter or, possibly, sodium channel) and water molecules enter $\mathrm{RBC}$ and cause their swelling. Though the detailed mechanism of RBC hemolysis is not known, increase in cell volume to a critical level is regarded as the main cause of hemolysis. The key intracellular event under apoptosis of RBC has been shown to be elevation of intracellular $\left[\mathrm{Ca}^{2+}\right]$ and related activation of potassium channels [3]. Export of $\mathrm{K}^{+}$and $\mathrm{Cl}^{-}$(the latter possible through $\mathrm{Cl}^{-}$channels or an inverted $\mathrm{Cl}^{-} / \mathrm{OH}^{-}$exchanger) together with water molecules leads to cell shrinkage. Calcium ionophores (ionomycin, A23187) have been shown to readily induce apoptosis of RBC and their apoptotic volume decreases [13].

In clinical practice, there is a need for development of new methodological approaches of assessment of the functional status of RBC, in order to relate their deformation behavior to different mechanisms of cell death. This would in turn allow more precise characterisation of the molecular mechanisms of anemia's etiology. We have previously reported on a low-angle light scattering technique for investigating biological cells. The theoretical and experimental foundations of this methodology have been described, based mostly upon studies on blood platelets [14-16]. Ehrlich ascite tumor cells have also been the subject for investigation of intracellular signalling systems and ion channels using this technique [17]. In the present work, we report on application and further development of the low-angle light scattering methodology to providing quantitative measurements of $\mathrm{RBC}$ volume transitions, which reflect development of apoptotic and/or necrotic scenarios of cell death.

\section{Materials and methods}

\subsection{Cells and solutions}

RBC were drawn from healthy volunteers or from male Wistar rats. Animals were preliminary narcotized with urethane at the dose of $1 \mathrm{~g} \mathrm{~kg}^{-1}$, and the blood was taken from the carotid artery. Experiments were performed at $20^{\circ} \mathrm{C}$ in solution containing $\left(\mathrm{mmol}^{-1}\right)$ : $\mathrm{NaCl}-140, \mathrm{KCl}-5$, HEPES -5 , glucose -5 , and $\mathrm{CaCl}_{2}-1$ (pH 7.4). Ammonia hemolysis of $\mathrm{RBC}$ was in the following medium $\left(\mathrm{mmol}^{-1}\right)$ : $\mathrm{NH}_{4} \mathrm{Cl}-140, \mathrm{KCl}-5$, HEPES - 5, glucose -5 , and $\mathrm{CaCl}_{2}-1$ (pH 7.4). 


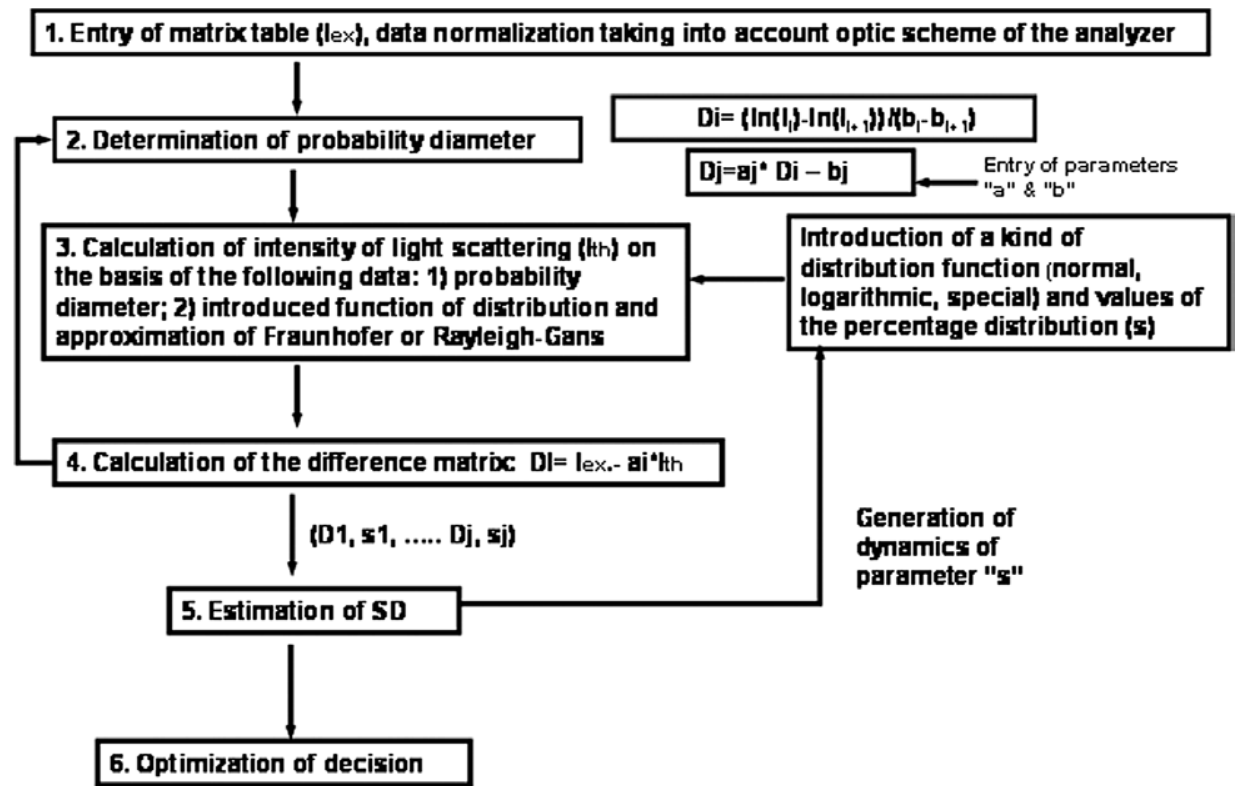

Fig. 1. Iteration method of determination of particle distribution by sizes. D - diameter; SD - standard deviation.

\subsection{Measurements of light scattering}

The intensity of the scattered light was measured with a Laser Particle Analyzer "LaSca" (Lumex Ltd, St-Petersburg, Russia) [14]. It allows kinetic investigations of cellular transformations, with evaluation of the distribution of the particles according to their dimensions at selected kinetic points. To determining the function of cell distribution according to their dimensions, which is calculated from the light scattering indicatrix being measured, it is necessary to solve the inverse scattering problem. This problem is ill-conditioned and does not have an unambiguous solution. To address this problem the following approach was applied: the scattering indicatrix was converted into a function that was near linearly depended on dimensions if additional coefficients were introduced. The values of the coefficients were established experimentally using standards with determined distribution functions. The following standards were applied: SRM659, SRM1003c, SRM1982 (NIST, USA), BSR070, BSR066 (Eur.), KMK005, KMK024 (Russia). Once the magnitude of the coefficients had been established (analyzer calibration), optimization of the inverse problem was carried out by iteration through comparison of theoretically calculated indicatrix (with revealed distribution functional) with experimental indicatrix. Figure 1 shows the programming flowchart, while Fig. 2 presents the results for distribution of standard materials.

\section{Results and discussion}

\subsection{Some theoretical foundations for application of the low-angle light scattering technique to investigating $R B C$}

To correctly evaluate the results obtained, it is necessary for the light beam coming through the measuring cell to diffract only once on a particle (cell) and not to rescatter on another particle (multiple 

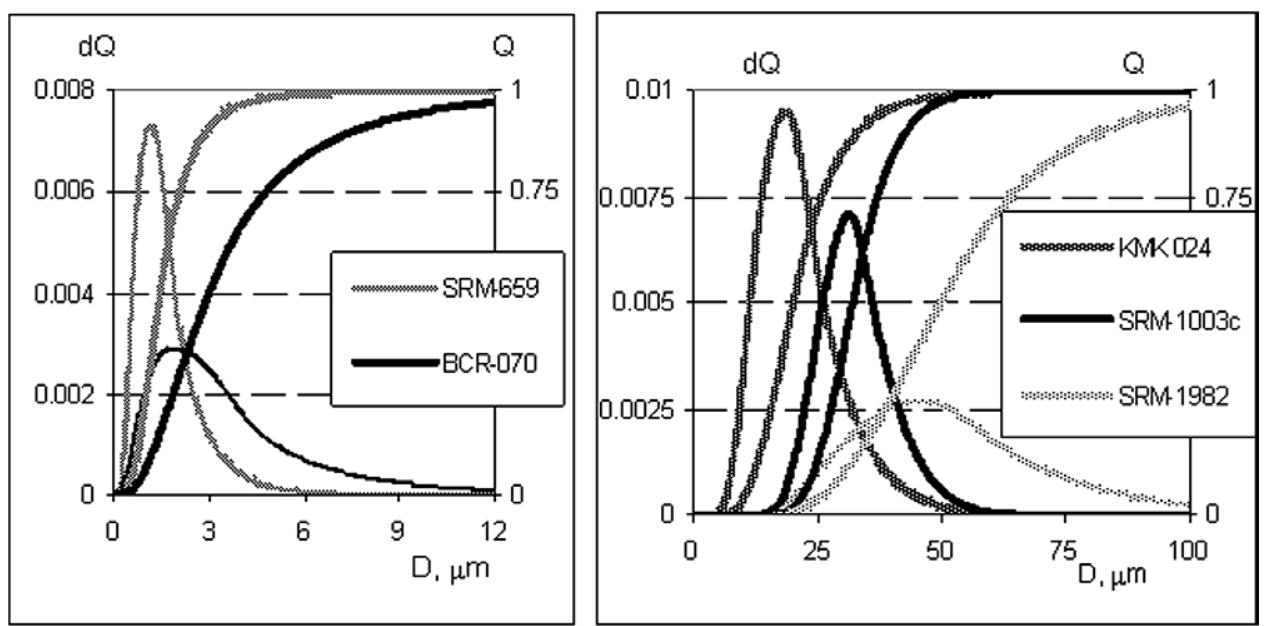

Fig. 2. Particle distribution by sizes for standard materials: SRM 659, SRM 1003c, SRM 1982 (NIST, USA), BCR-070 (Eur.), KMK 024 (Russia).
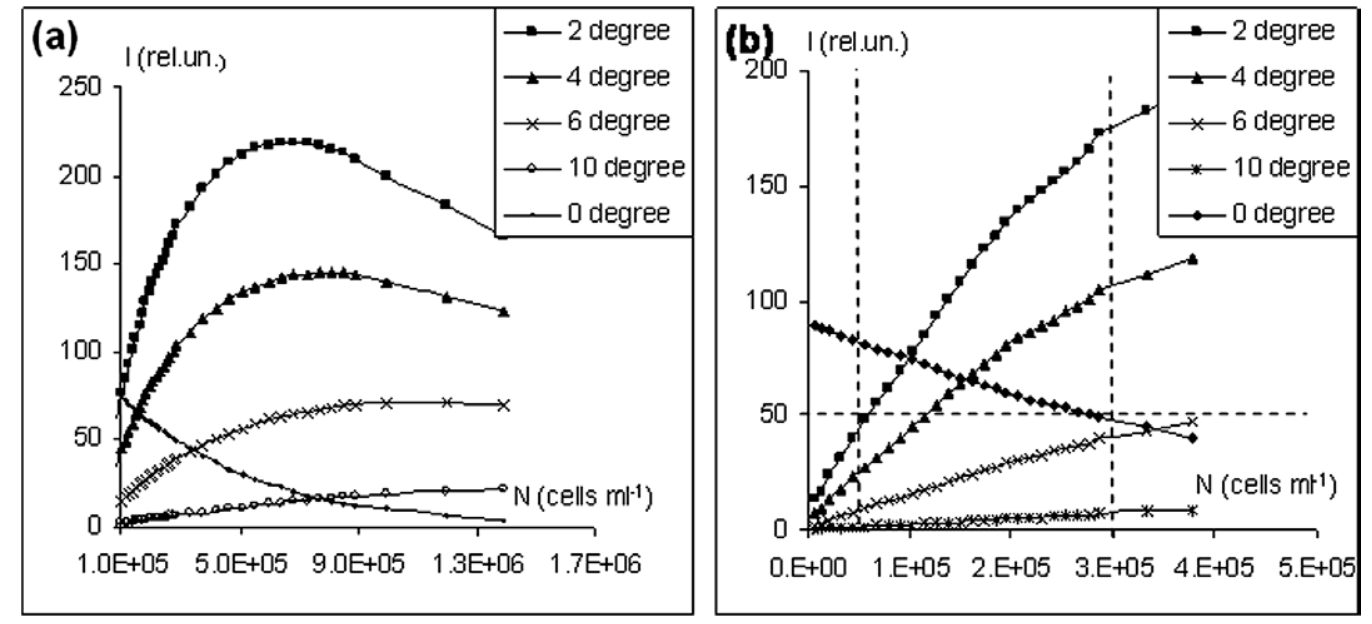

Fig. 3. Dependence of light scattering intensity $(I)$ in the range of $0-10$ degrees upon concentration of human RBC in isotonic medium. Values on the abscissa are given in the scientific number format $\left(2 \mathrm{E}+06 \rightarrow 2 \cdot 10^{6}\right)$. Graph (a) shows the complete range of concentrations; graph (b) shows the operating range.

scattering). It is attained through limitation of the particles' concentration. The criterion for single scattering is retention of a linear dependence between intensity of light scattering and concentration of the particles. Figure 3 shows dependence of the light scattering intensity at different angles upon concentration of RBC. The single scattering criterion was maintained at RBC concentrations of not more than $3 \times 10^{5}$ cells ml ${ }^{-1}$ (Fig. $3 \mathrm{a}$ ); actually cell concentrations used were in the range $(0.5-3) \times 10^{-5}$ cells ml $^{-1}$ (Fig. 3b). To satisfy the criterion in experimental work, the instrumentation indications at an angle of zero degree with light transmission of 50-70\% was used. In practice, blood taken from an organism was diluted approximately 30,000-50,000 times in two steps: $5 \mu \mathrm{l}$ of blood was added to $495 \mu \mathrm{l}$ of isotonic water (100-fold dilution), then $200 \mu \mathrm{l}$ of this suspension was placed in the cuvette with $5800 \mu \mathrm{l}$ of medium (further 300-fold dilution). 


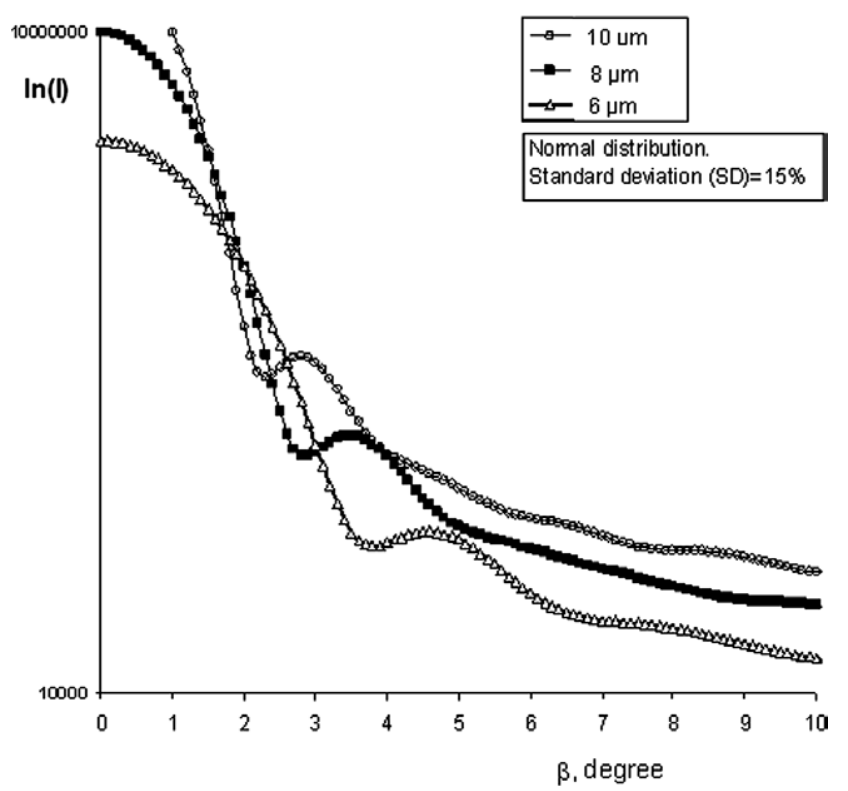

Fig. 4. Theoretical indicator functions (indicatrix) for particle ensembles with their specified distribution by sizes $(6,8$ and $10 \mu \mathrm{m})$.

The average diameter of normal $\mathrm{RBC}$ is about $8 \mu \mathrm{m}$, with most cells being in the range from 5 to $11 \mu \mathrm{m}$. For modeling purposes these cells could be considered as spherical particles of $8 \mu \mathrm{m}$ with normal distribution and standard deviation value of $15 \%$. Figure 4 illustrates the dependence of light intensity $(\ln I)$ upon scattering angle $(\beta)$ for particles with diameter $8 \mu \mathrm{m}$ (model of RBC), 6 and $10 \mu \mathrm{m}$. The calculation was based on Mie theory and predicted an increase of intensity of the scattered light with increase of RBC size (swelling) within two angle ranges, 0.2-1.5 and 6-12 degrees. Cell shrinkage was characterized by an opposite dependence. Within the range 1.5-6 degrees, the signaling behavior under cell volume changes had ambiguous character. The signals in this range (the 1st diffraction minimum) were sensitive to the RBC shape changes, but their utilization in analysis of cell volume changes was problematic due to ambiguity of interpretation of the data obtained.

\subsection{Study of hemolysis by the low-angle light scattering method}

\subsubsection{Osmotic hemolysis}

When placing RBC into hypotonic medium, the following transformation of cells can be seen. From the initial disc-shaped state they become spherical shaped with one large invagination. With further decreasing osmotic pressure the cavities increase in number but decrease in size, turning into several small invaginations. The RBC eventually transform into large ideal smooth spherocytes [18], known as stomatocytes, and the process of transformation is defined as stomatocytosis.

Studies of RBC swelling were conducted by placing cells into isotonic medium and then adding small volumes of distilled water at intervals of 2-3 min. There was no hemolysis in the medium with tonicity down to $112 \mathrm{mOsm}$, and the signal values at all the angles remained constant within the signal fluctuations. (It should be noticed that hemolysis would probably have occurred in hypo-osmotic medium with a higher tonicity but at longer intervals of exposure.) Figure 5 demonstrates stability of RBC in the hypo-osmotic media with tonicities sufficing for hemolysis to take place. Dilution with water caused 


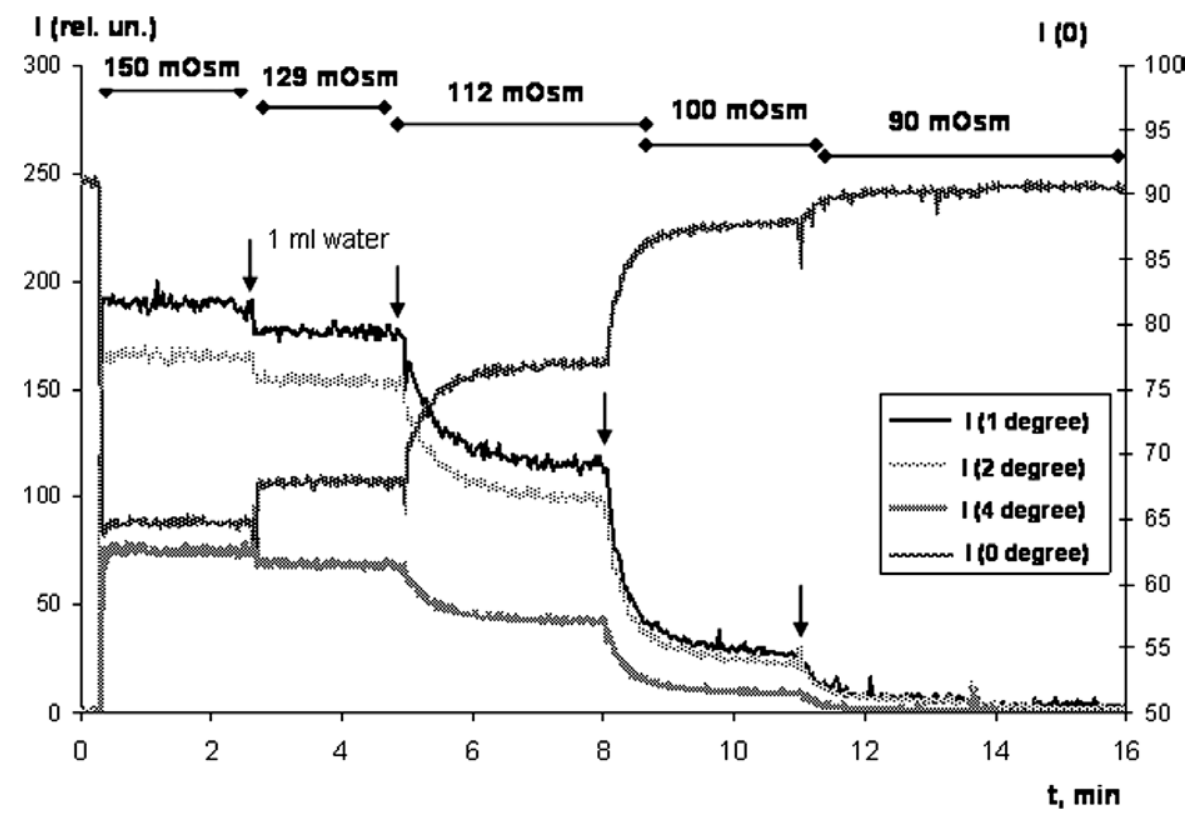

Fig. 5. Changes of light scattering intensity at four angles $(0,1,2$ and 4 degrees) under hypotonic loading. The values of tonicity (mOsm) over the course of the incubation are shown.
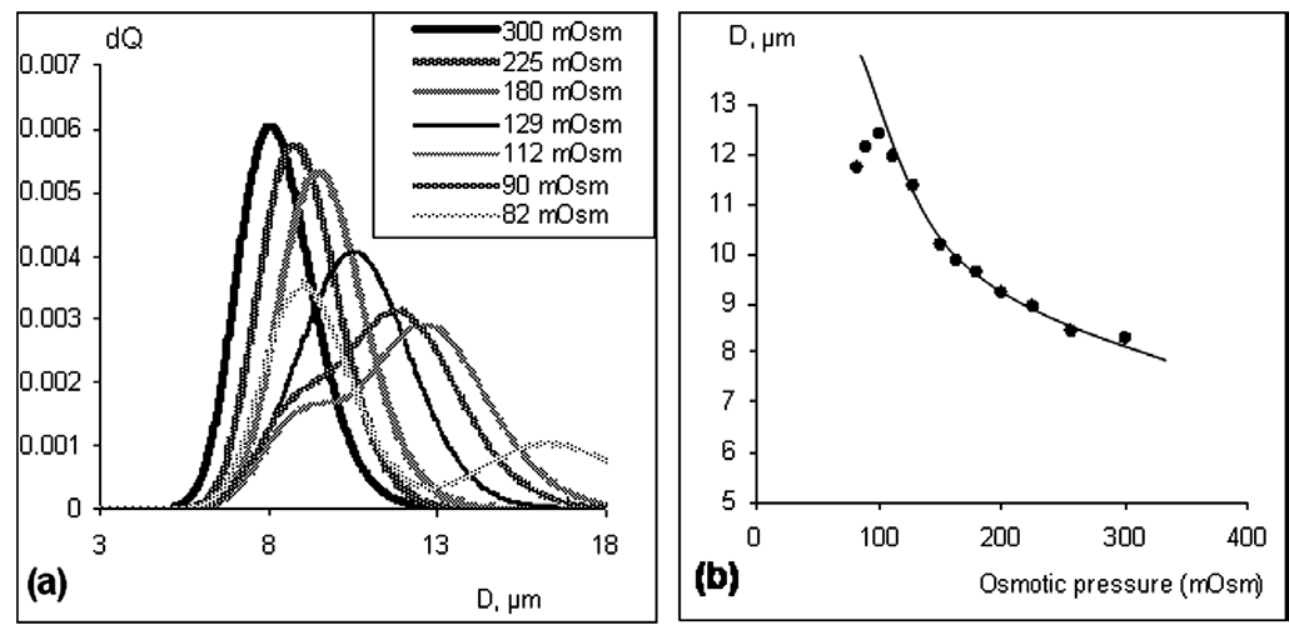

Fig. 6. Changes of RBC sizes in hypotonic medium. (a) The particle distribution under different medium tonicity. (b) Dependence of the average cell volume diameter upon the medium tonicity.

rapid changes of the signals, the zero degree signal being characterized by an increase of the light scattering intensity $(I)$. Further enhancement of zero degree signal and decrease of the signal intensities at low angles reflected $\mathrm{RBC}$ hemolysis.

The RBC dimensions were determined under various osmotic pressures according to the algorithm described in Section 2.2. The data obtained are presented in Fig. 6a. Initially, under decrease of osmotic pressure the distribution had a single-mode character. However, when osmotic pressure was below 125 mOsm a two-mode distribution was observed: RBC with dimensions above a critical level were 


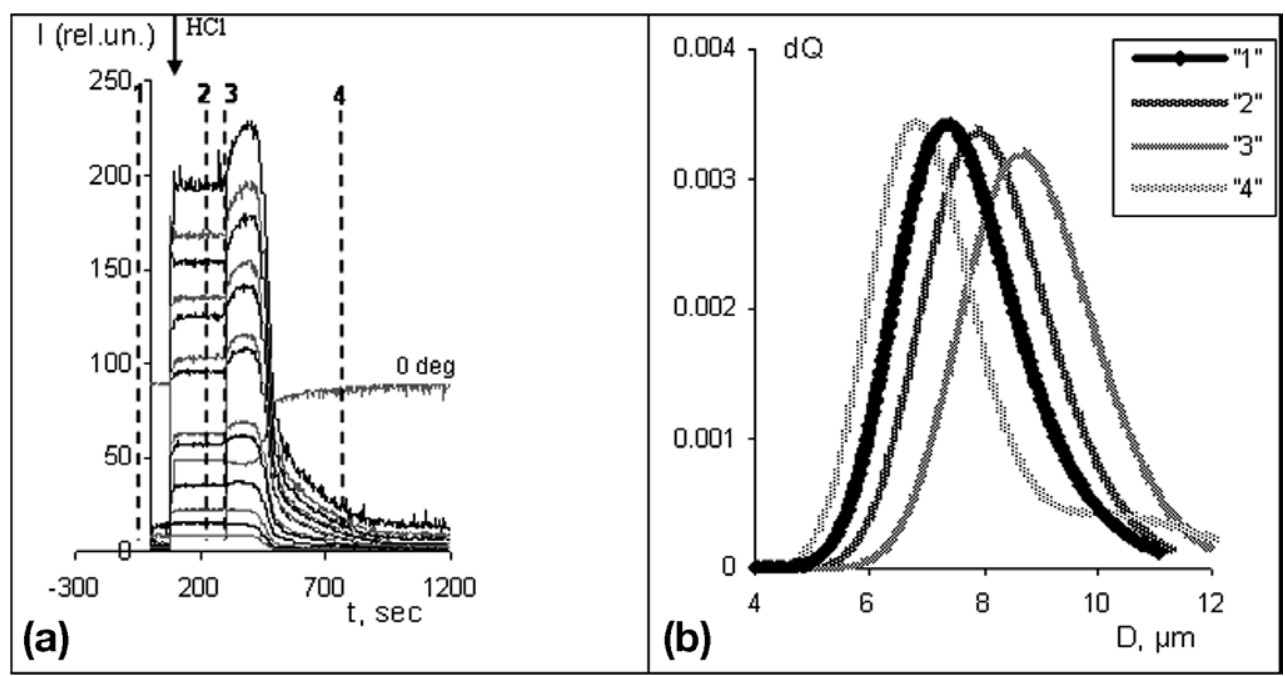

Fig. 7. Acidic hemolysis of RBC. (a) Dynamics of light scattering intensity upon introduction of $\mathrm{HCl}$ (pH 3.1). (b) Distribution of RBC by sizes at selected kinetic points of the hemolytic process. On (a), traces in decreasing signal height order at around 200 seconds (degrees for registration of light scattering): 1.25, 1.75, 2.25, 3.25, 3.50, 4.00, 3.75, 4.50, 5.00, 0, 5.50, 6.60, 7.50, 9.00 .

lysed, and only relatively small cells continued to register a signal. The critical diameter of the cells was evaluated; Fig. $6 \mathrm{~b}$ shows the dependence between average volume diameter and osmotic pressure of the medium. RBC in the medium with osmotic pressure down to $130 \mathrm{mOsm}$ behaved as ideal osmometers, quickly tracking the osmotic pressure: there was an inverse relation between the cell volume and osmotic pressure. At lower osmotic pressures this relation was no longer evident, the cells being hemolysed upon reaching the critical size near $13-14 \mu \mathrm{m}$.

\subsection{2. $\mathrm{RBC}$ hemolysis under change of $\mathrm{pH}$}

Change of $\mathrm{pH}$, either due to acidifying the outer medium or due to alkalizing the intracellular medium, activates the $\mathrm{Cl}^{-} / \mathrm{OH}^{-}$exchanger (band 3 protein) leading to influx of chlorine anion into cells and concurrent influx of sodium ions and water molecules. As a result, there should be an initial RBC swelling observed. Indeed, under acidification of isotonic medium containing suspension of RBC an increase of signal intensity in the range of very low angles (0.5-4 degrees, Fig. 7a) and in the range of distant angles (9-12 degrees, not shown here because of a very small signal amplitude) was observed, which is also evident from theoretical calculations (see Section 3.1) on increase of cell volume. An assessment of the particle distribution was carried out according to their sizes at different kinetic points (1 to 4) of the process: (1) for initial suspension of RBC; (2) at the point of maximal signal intensity for very low angles; (3) at $50 \%$ of hemolysis on the basis of dynamics of the signal at 0 degree; and (4) at the end of hemolysis. Distribution of the data is presented in Fig. 7b. It can be seen that cell size increased not only at the initial moment before hemolysis began (point 2), but also during hemolysis (point 3). Only a small proportion of the RBC population (less than 5\%) was smaller as compared with their initial size (point 4).

It is notable that the RBC do not achieve the critical size for hemolysis to occur (near $13 \mu \mathrm{m}$ under osmotic hemolysis), hemolyzing at smaller sizes. Two possible explanations for this are: (1) activation of $\mathrm{Cl}^{-} / \mathrm{OH}^{-}$exchanger could weaken the bonds between this protein and the cytoskeleton, leading to breakdown of the wireframe matrix of the cells; (2) the cell membrane is unstable under low $\mathrm{pH}$ val- 

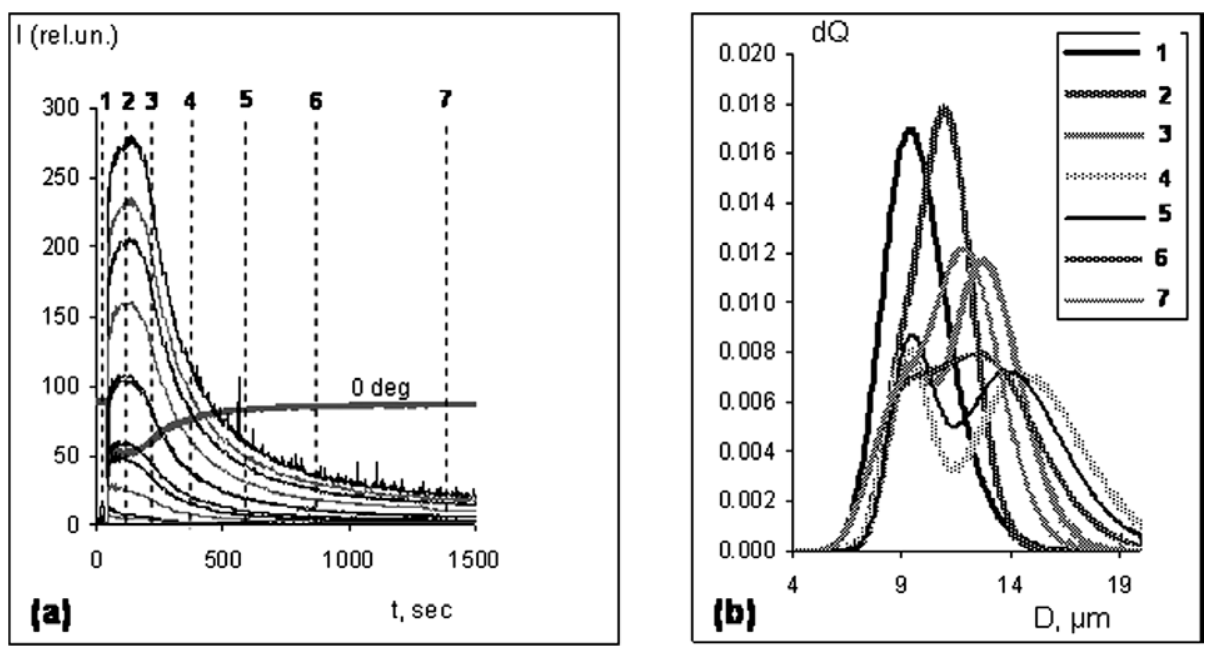

Fig. 8. Hemolysis of $\mathrm{RBC}$ in the ammonia $\left(\mathrm{NH}_{4} \mathrm{Cl}\right)$ medium. (a) Dynamics of the light scattering intensity upon introduction of RBC into medium containing ( $\left.\mathrm{mmol}^{-1}\right)$ : $\mathrm{NH}_{4} \mathrm{Cl}, 105 ; \mathrm{NaCl}, 35 ; \mathrm{KCl}, 5$; HEPES, 5; glucose, 5; and $\mathrm{CaCl}_{2}, 1$ ( $\mathrm{pH}^{7.4}$ ). (b) Distribution of RBC by their sizes at selected points of the hemolytic process. On (a), traces in decreasing signal height order at around $100 \mathrm{sec}$ (degrees for registration of light scattering): 1.25, 1.75, 2.25, 3.25, 3.50, 4.00, 4.50, 0, 5.00, 5.50, 7.50, 9.00. Numbers $1-7$ designate the selected kinetic points.

ues. To test the first possibility, experiments were conducted under conditions of activated $\mathrm{Cl}^{-} / \mathrm{OH}^{-}$ exchanger at physiological $\mathrm{pH}$. RBC were placed into isotonic medium with ammonia replacing sodium ions ( $\mathrm{mmol}^{-1}$ ): $\mathrm{NH}_{4} \mathrm{Cl}, 140$; $\mathrm{KCl}, 5$; HEPES, 5; glucose, 5; and $\mathrm{CaCl}_{2}, 1$ (pH 7.4). $\mathrm{RBC}$ swelling was observed, as indicated by primary increase of the signal at very low angles, followed by total hemolysis. The process was also observed in more protective conditions, with sodium ions being partially replaced by ammonia ions in isotonic medium of the following composition $\left(\mathrm{mmol}^{-1}\right)$ : $\mathrm{NH}_{4} \mathrm{Cl}, 105$; $\mathrm{NaCl}, 35$; $\mathrm{KCl}, 5$; HEPES, 5; glucose, 5; and $\mathrm{CaCl}_{2}, 1$ (pH 7.4). Figure 8a shows the dynamics of RBC hemolysis under these conditions, while Fig. 8b shows the distribution of particles of different sizes at selected kinetic points. Rapid cell swelling occurred almost immediately after placing RBC into ammonia medium; even when close to the initial conditions the size of RBC increased to above normal (point 1). At the point of maximal increase of the signal for very low angles (2 degrees) RBC diameter was near $11 \mu \mathrm{m}$. With persisting conditions of hemolysis the size of RBC increased further and, similar to that obtained for osmotic hemolysis, reached a diameter slightly greater than $14 \mu \mathrm{m}$. These observations are not consistent with the supposition that deformation behavior was related to breaking the bonds between the $\mathrm{Cl}^{-} / \mathrm{OH}^{-}$exchanger and cytoskeleton. Most likely, the low $\mathrm{pH}$ values affect stability of the plasma membrane. A dependence upon divalent cations is also possible: a similar rate and completeness of hemolysis in comparison with that induced by $\mathrm{HCl}$ was observed at a less acidic $\mathrm{pH}$ of 4.1, when induced by citric acid (Fig. 9). In view of the fact that citrate is a calcium chelating agent we suggest that the changes of deformation characteristics of plasma membrane depends not only upon $\mathrm{pH}$, but also upon concentration of calcium ions in the plasma membrane boundary layer.

Hemolysis of RBC can be properly characterized not by dynamics of signal changes in zero degree (the light scattering signals are more suitable for this), but through differential characteristics of kinetics (derivation of velocity) - this is the method of acid erythrograms developed by Terskov in 1957 [19]. Figure 9 shows data on acidic hemolysis (hydrochloric acid, citrate) and hemolysis in $\mathrm{NH}_{4} \mathrm{Cl}$ medium. The latter was more protracted compared with acidic hemolysis, probably because of increase in size of RBC 


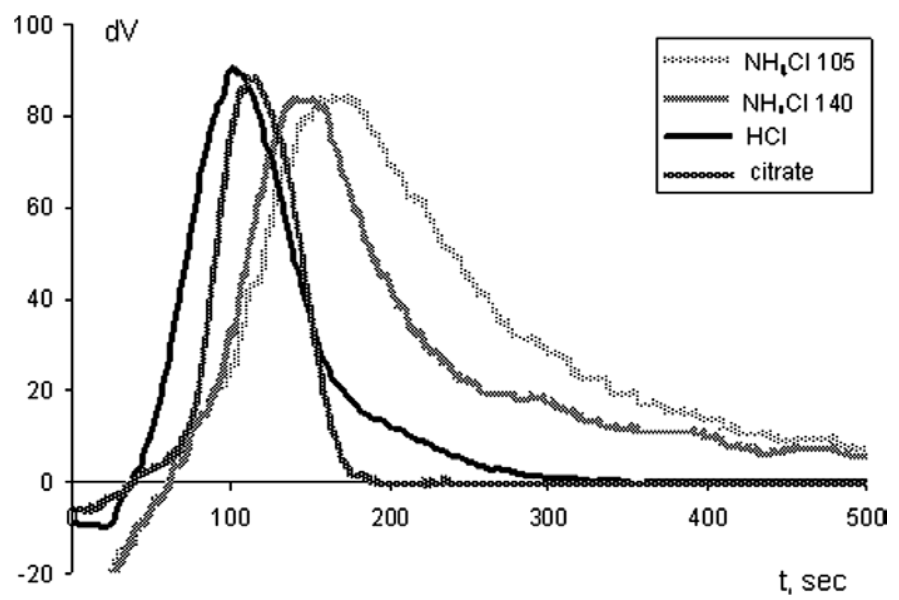

Fig. 9. Erythrograms of RBC hemolysis. (1) $\mathrm{NH}_{4} \mathrm{Cl} 105$ (mmoll $\left.{ }^{-1}\right): \mathrm{NH}_{4} \mathrm{Cl}, 105 ; \mathrm{NaCl}, 35 ; \mathrm{KCl}, 5$; HEPES, 5; glucose, 5; and $\mathrm{CaCl}_{2} 1$ (pH 7.4). (2) $\mathrm{NH}_{4} \mathrm{Cl}$ 140: $\mathrm{NH}_{4} \mathrm{Cl}, 140$; KCl, 5; HEPES, 5; glucose, 5; and $\mathrm{CaCl}_{2}, 1$ (pH 7.4). (3) $\mathrm{HCl}: \mathrm{HCl}, 8$ (pH 3.1). (4) citrate: citrate, $10(\mathrm{pH} 4.1)$.

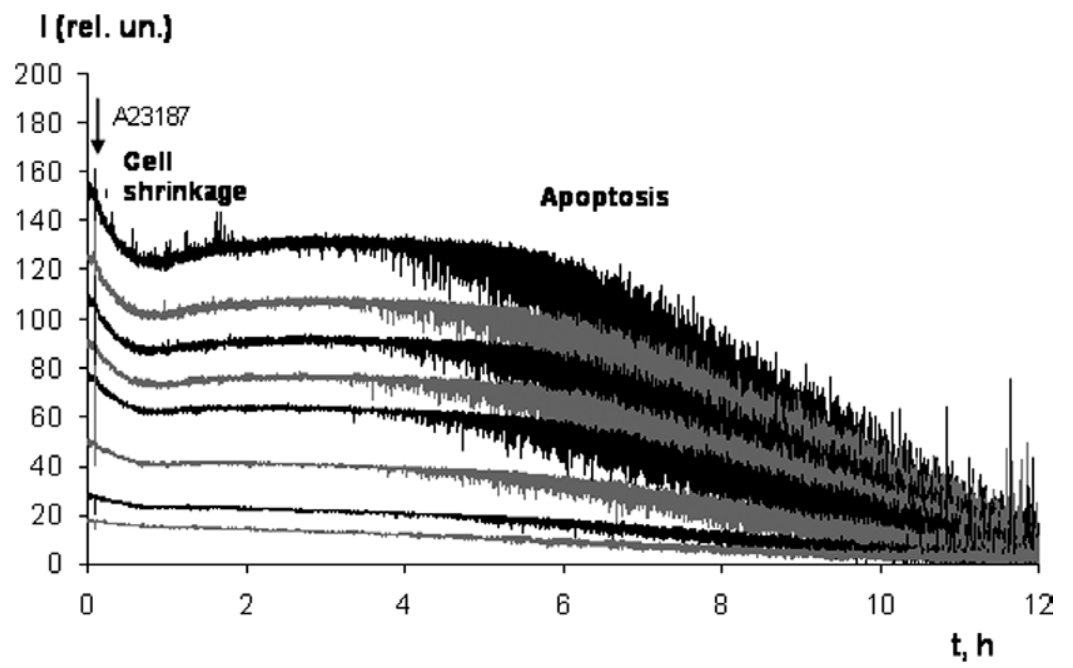

Fig. 10. RBC shrinkage followed by development of apoptosis under action of calcium ionophore A23187 $\left(1 \mu\right.$ mol $\left.1^{-1}\right)$. Changes of light scattering intensity in the range of 1.5-6.5 degrees. Traces in decreasing signal height order (degrees for registration of light scattering): $1.50,2.25,2.50,3.00,3.75,4.5,5.50,6.50$.

due to swelling. One might expect that assessments of RBC stability obtained under osmotic loading are better correlated with data on hemolysis in $\mathrm{NH}_{4} \mathrm{Cl}$ medium, as compared with acidic hemolysis.

\subsection{Study of apoptosis using the low-angle light scattering method}

It is well known that calcium ionophores (ionomycin, A23187) induce apoptotic volume decrease corresponding with apoptosis of RBC [20]. Figure 10 represents data on A23187 action $\left(1 \mu \mathrm{mol}^{-1}\right)$ on RBC. Figure 11 shows data on distribution of the particles due to their sizes in different periods of the process. A slow initial volume decrease (cell shrinkage) lasting for 1 hour was observed, as evident from a decrease in light scattering intensity at very low angles. The average cell diameter was estimated to be 


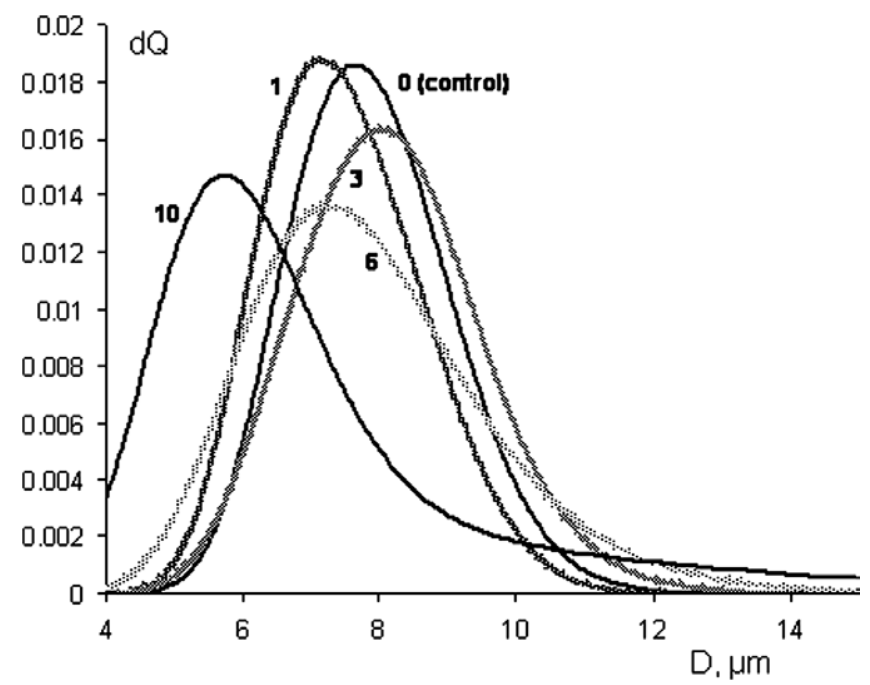

Fig. 11. Distribution of RBC by their sizes at selected kinetic points $(0,1,3,6$ and $10 \mathrm{~h})$ of the apoptotic process. The time points are shown (hours).

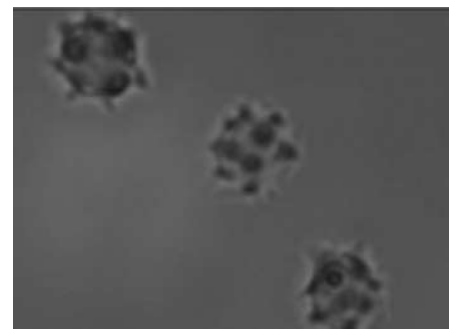

(a)

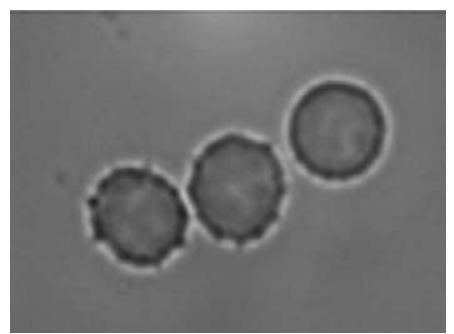

(b)

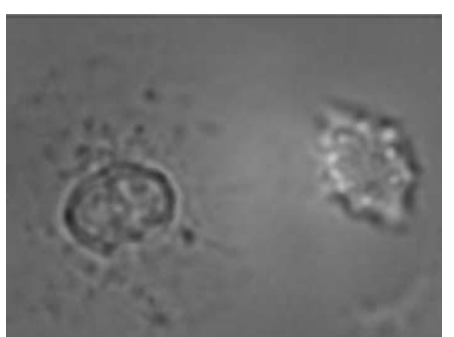

(c)

Fig. 12. Microscopic photo of RBC under action of A23187 $\left(1 \mu \mathrm{moll}^{-1}\right)$. At (a) 2 hours, (b) 4 hours and (c) 8 hours after the action. $\times 1000$.

near $7.4 \mu \mathrm{m}$ (distribution for 1 hour). After that the cell population remained rather stable for $3-4$ hours. A minor volume increase characteristic of the distribution for 3 hours was observed. Development of the apoptotic program then began, with increasing fluctuations of all the signals. Distribution of the particles enlarged according to their sizes (6 hours); portions of both small and large particles are augmented. These two indices (enlargement of fluctuation and broadening of distribution) testify to the appearance of agglomeration. The population after 10 hours was characterized mostly by small particles, but there was also a big proportion of cells as large agglomerates (the signal fluctuation had grown greatly). Figure 12 shows photomicrographs of RBC after induction of $\mathrm{Ca}^{2+}$ influx: soon after induction ( 2 hours) the cell volume decreased (Fig. 12a), at 4 hours the apoptotic process had begun to develop (Fig. 12b), and at 8 hours the main phase of apoptosis was underway (Fig. 12c). It is clearly seen that after 2 hours exposure to A23187, RBC were mostly transformed to be crenated cells with spikes of the same shape equally distributed on the cell surface (Fig. 12a). These RBC are identified as echinocytes based on their morphological features $[18,21,22]$. Two hours from this time point the RBC become spherical, their cell membrane being of uneven shape (in contrast to spherocytes) (Fig. 12b). In the population of RBC, an emergence of agglomerates (ensembles of 2-5 cells) can be seen; one of agglomerate is shown on 


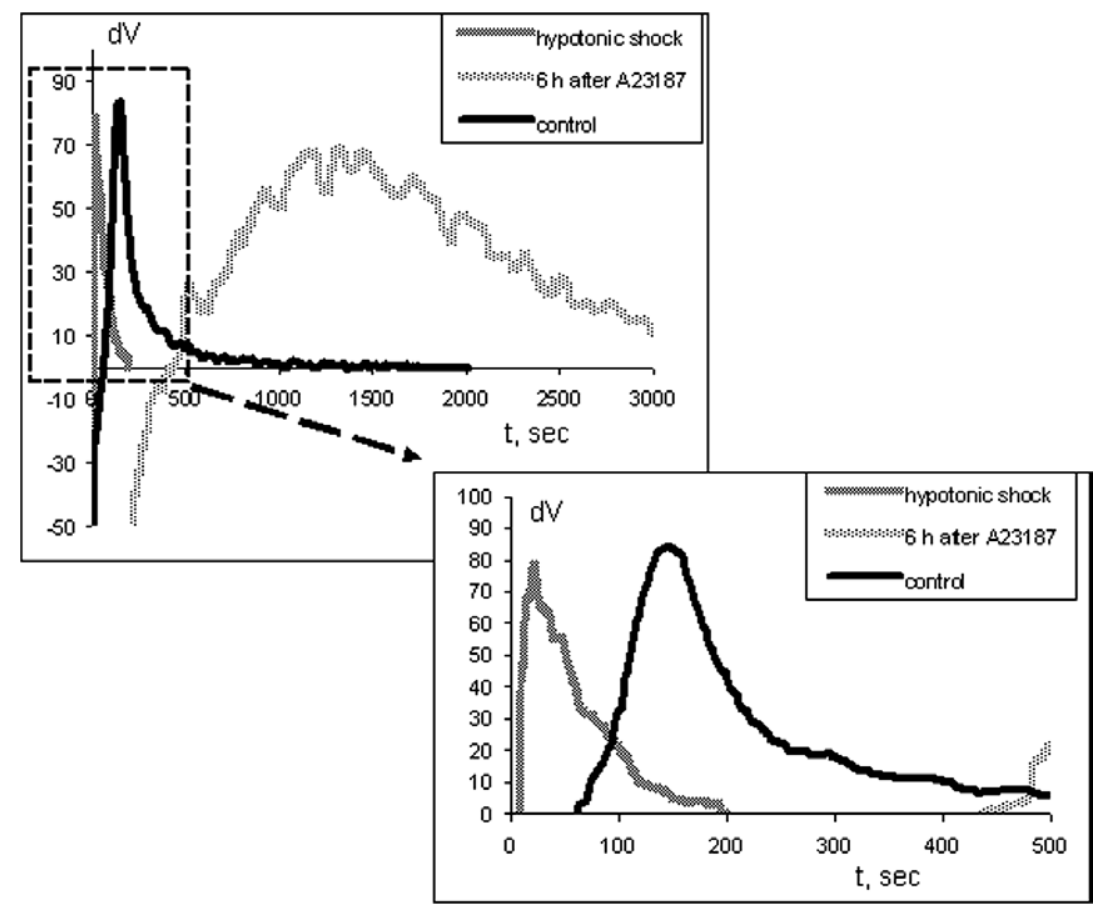

Fig. 13. Erythrograms of $\mathrm{RBC}$ hemolysis in ammonia medium $\mathrm{NH}_{4} \mathrm{Cl} 140$ (composition given in legend to Fig. 9). The data represented for RBC after hypotonic shock, for RBC in apoptotic state, and for control RBC.

Fig. 12b. Finally, 8 hours after the induction of apoptosis the process of defragmentation of the cells was observed (Fig. 12c). At this stage, large groups of RBC were evident comprising up to 10 associated cells. We conclude from the data represented here that (1) echinocytes are a preapoptotic form of RBC and (2) the apoptotic process is accompanied by aggregation (agglomeration) of RBC.

We have observed a similar scenario of RBC transformation when placing cells into hypertonic medium (950 mOsm). In this case, the kinetic of the process is more protracted with apoptosis developing within 10-12 hours (data not shown). Lang et al. [3,20] found that the same RBC transformation scenario developed after 2 days' starvation (energy depletion) of cells and oxidative stress caused by addition of $1 \mathrm{mmol}^{-1}$ of the oxidant tert-butyl-hydroperoxide (tBOOH).

\subsection{Comparison of erythrograms of different states of $R B C$}

In order to understand erythrograms of hemolysis as a methodological approach to estimating the status of RBC population, it is reasonable to compare erythrograms obtained under different RBC states, namely after hypotonic shock (stomatocytes) and during apoptotic state (echinocytes). Furthermore, it has been demonstrated that shrunk RBC due to exposure to A23187 are more stable to hypotonic loading than control RBC [23].

RBC were subjected to hypotonic shock according to the following scheme: freshly obtained RBC were placed for $30 \mathrm{~min}$ into hypotonic medium with tonicity $150 \mathrm{mOsm}$ (2-fold dilution of the medium with distilled water). The cells were then placed back into the initial normotonic medium and investigated after $15 \mathrm{~min}$. The apoptotic state was induced in freshly isolated RBC by addition of A23187, $1 \mu \mathrm{mol} 1^{-1}$, followed by incubation for 6 hours. Figure 13 shows erythrograms obtained for the cells 


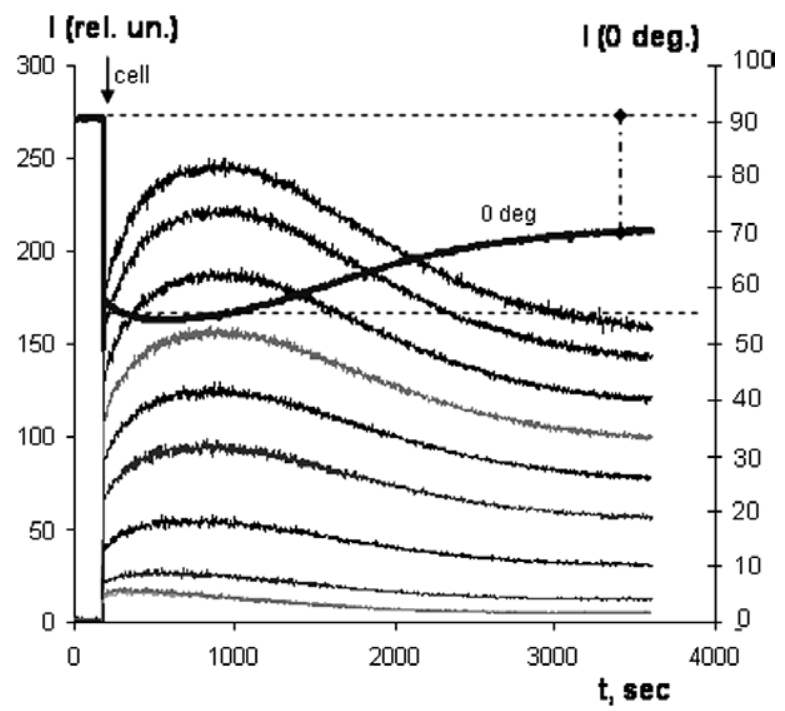

Fig. 14. Hemolysis of apoptotic $\mathrm{RBC}$ in the ammonia medium $\mathrm{NH}_{4} \mathrm{Cl} 140$ (composition given in legend to Fig. 9). The apoptotic state was induced by 6 hours' exposure to A23187. Traces in decreasing signal height (degrees for registration of light scattering): $1.50,2.00,2.25,0,2.50,3.00,3.75,4.5,5.50,6.50$. The vertical dashed line indicates the extent of incomplete hemolysis.

in hemolytic ammonia medium ( $\mathrm{mmol}^{-1}$ ): $\mathrm{NH}_{4} \mathrm{Cl}, 140$; $\mathrm{KCl}$, 5; HEPES, 5; glucose, 5; and $\mathrm{CaCl}_{2}, 1$ (pH 7.4). This figure shows the control curve, the curve representing hypotonic shock, and that of apoptotic RBC. Since there was a sharp distinction between the time of hemolysis for RBC after hypotonic shock and for apoptotic cells, the results are presented on two different scales. It is evident that RBC after hypotonic shock underwent rapid hemolysis (during 20-40 seconds), regardless of the fact that they were placed back into isotonic medium. Conversely, apoptotic RBC underwent a long-lasting initial transformation (Fig. 14) and only $15 \mathrm{~min}$ after that they began to slowly hemolyze. However, hemolysis was incomplete: less than $40 \%$ of RBC hemolysed within an hour (note the vertical segment near the end of the process, Fig. 14). By comparison, the same apoptotic RBC undergo a very fast hemolysis in the acidic medium (loading with $\mathrm{HCl}, \mathrm{pH}$ 3.0) and there is no initial increase of signal intensity, i.e. there is no prehemolytic swelling of the cells lysing due to acidic destruction of the membrane (Fig. 13). Application of the ammonia testing system is preferable to the acid loading system, because in the former echinocytes-like cells and stomatocytes-like cells can be adequately differentiated and identified. The use of the acidic loading as a testing system could probably be justified only at moderate acidity levels $(\mathrm{pH} \sim 4.0)$.

Under such conditions of moderate acidity we conducted toxicological experiment in vitro to investigate how RBC hemolysis is affected by organophosphates. Hemolysis was induced by introduction of hydrochloric acid into suspension of RBC placed in physiological salt solution, with a final $\mathrm{pH}$ of 4.2. Under these conditions, hemolysis is more protracted as compared to that illustrated in Fig. 9. Before testing, RBC had been incubated with various concentrations of diisopropylfluorophosphate (DFP) for 1 hour. Figure 15 shows the erythrograms of the control cells and those exposed to DFP. It is evident that the RBC incubated with DFP hemolysed sooner than control cells. Quantitatively, this effect was evaluated after the "time of maximal hemolysis" - T(gem), the time period from acidic loading to beginning of maximal velocity of hemolysis (Fig. 15a). The dose dependence of T(gem) upon concentration of DFP (logarithmic coordinate) is given on Fig. 15b: $\mathrm{EC}_{50}$ is estimated to be around $40 \mu \mathrm{mol}^{-1}$. This research, 


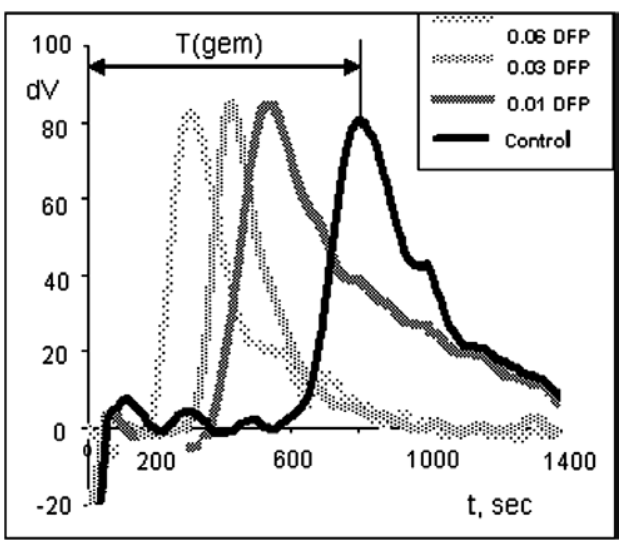

(a)

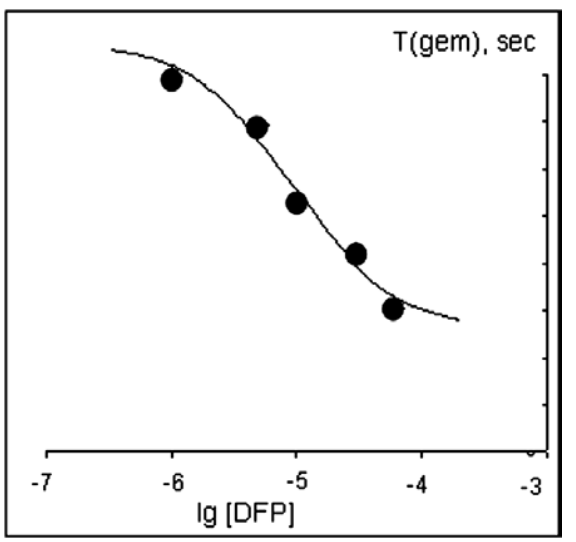

(b)

Fig. 15. (a) Erythrograms of RBC hemolysis one hour after incubation with DFP (the doses in mmol $1^{-1}$ are shown) and (b) dependence of the maximal hemolysis time upon concentration of DFP (presented in logarithmic coordinates).

although preliminary, demonstrates the capabilities of the approach for studying toxic or pharmaceutical agents.

On the basis of our data and a literature review the following paradigm of RBC transformation can be set up (Fig. 16). Original discocytes undergo swelling in hypotonic medium, initially forming concave or cup-shaped stomatocytes (see bottom right picture). Further enhancement of hypotonic loading causes transformation of RBC into large spherical cells having smooth surface (a big spherocyte - see upper right picture). Upon reaching a critical size of 13-14 $\mu \mathrm{m}$ in diameter, the cells undergo "bursting" (although separate cells can reach a bigger size). Because the process is due to disturbance of the membrane integrity, this type of death is classified as necrosis. By tradition this type of RBC death is known as "hemolysis", so we consider "necrosis" and "hemolysis" to be the equivalent terms designating a process distinct from apoptotic death of RBC.

Under pathophysiological conditions hemolysis is most often preceded by swelling of RBC, so this process is designated as necrotic volume increase (NVI) [10]. The trigger of this process is activation of $\mathrm{Cl}^{-} / \mathrm{OH}^{-}$exchanger (the band 3 protein), which takes place in acidic medium - a very logical reaction, because one of the basic functions of RBC is maintaining the blood $\mathrm{pH}$ homeostasis. Intracellular alkalization also leads to cell swelling (e.g. when placing RBC into ammonia medium). One would expect that reduction of $\left[\mathrm{HCO}_{3}^{-}\right]$in the medium to induce swelling of $\mathrm{RBC}$, but this effect can be compensated by hemoglobin $(\mathrm{Hb})$ fixation of oxygen: fixation of one oxygen molecule leads to release of two protons and acidification of intracellular $\mathrm{pH}$ - the so-called Jacobs-Stewart cycle [24,25]. That is why normally there is no RBC swelling in the pulmonary microvessels [26]. However, concentration of the bicarbonate anion may be a critical factor in hypoxic conditions. In practice, under pathophysiological conditions the $\mathrm{RBC}$ undergo the same stages of transformation leading to hemolysis that can be seen under hypotonic loading, but under the former conditions hemolysis may occur without achieving the critical size by the cells at the expense of changes in deformational characteristics of plasma membrane. In this connection there is a need to separately examine the RBC hemolysis which is dependent on $\mathrm{Hb}$ defects, when insoluble forms of $\mathrm{Hb}$ are produced. Translocation of $\mathrm{Hb}$ to the plasma membrane may greatly influence its deformational characteristics [27,28], and hemolysis can take place without preceding RBC swelling.

An opposite scenario of RBC death develops when cells are placed in hypertonic medium and under apoptosis. The key reaction of cell shrinkage as a sign of the apoptotic process is elevation of intracellu- 


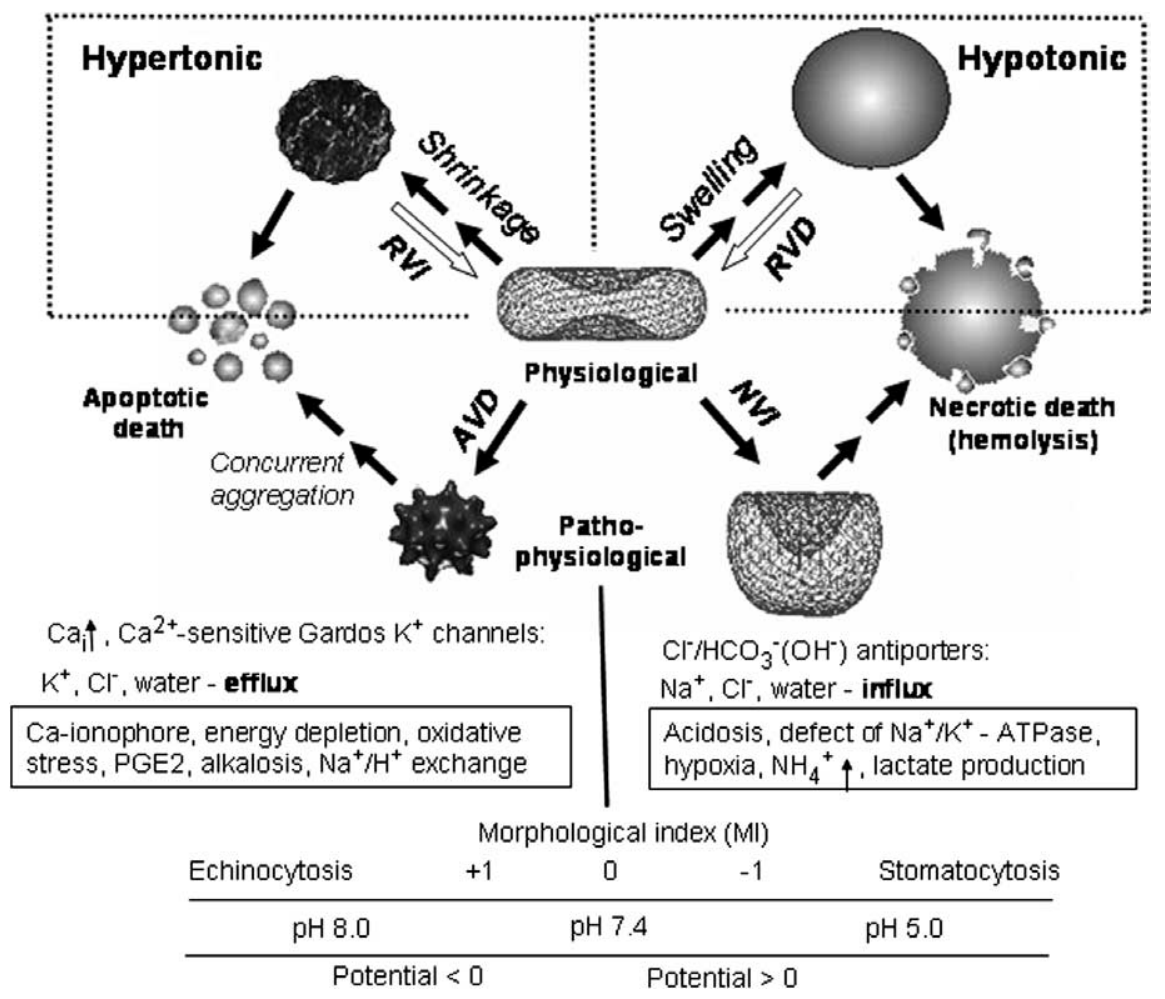

Fig. 16. A generalised scheme for RBC transformations under tonicity loading and in pathophysiological states. Regulatory volume decrease, RVD; regulatory volume increase, RVI; apoptotic volume decrease, AVD; necrotic volume increase, NVI. See text for further explanation.

lar calcium ions [3] followed by activation of $\mathrm{K}^{+}$channels $\left(\mathrm{Ca}^{2+}\right.$-activated Gardos $\mathrm{K}^{+}$channel). Efflux of $\mathrm{K}^{+}$and $\mathrm{Cl}^{-}$together with efflux of water molecules results in cell shrinkage, which is the apoptotic volume decrease (AVD). Initially, echinocytes are generated - the RBC having spikes on their plasma membrane. The subsequent transformation of the cells is a slow process taking several hours (the fundamental distinction from hemolysis). After that, the rounded RBC with uneven membranes develop from echinocytes. The phosphatidylserine asymmetry of the plasma membrane is broken; this leads to appearance of negatively charged molecular groups on the cell surface and the RBC begin to agglomerate as a result of this (aggregation concomitant with apoptosis) [29]. The RBC apoptosis leads to formation of small cellular fragments. In addition to hypertonic shock, the apoptotic process can be induced by glucose deprivation, oxidative stress, action of $\mathrm{PGE}_{2}$ and activation of $\mathrm{Na}^{+} / \mathrm{H}^{+}$exchange $[5,30,31]$. Effects of NO (and peroxynitrite?) on RBC can be of two kinds depending on the dose. On one hand, NO being a radical may cause oxidative stress in the cells resulting in apoptosis; on the other hand, binding of NO with $\mathrm{Hb}$ may cause translocation of $\mathrm{Hb}$ to plasma membrane resulting in hemolysis $[32,33]$.

To a certain extent, the scheme of RBC transformation coincides with the morphological nomenclature of Bessis [18]. Citing from Gedde [34]:

"Flattened or elongated cells with spikes were scored as stage +1 or +2 , whether the spikes were broad or fine, with number of spikes distinguishing stages +1 and +2 . Stage +3 cells were rounded with broad spikes; stage +4 cells were round with fine spikes; and stage +5 cells were smooth spherocytes. Stage -1 stomatocytes had one large invagination, with no remaining trace of biconcavity. 
Stage -2 cells had one main invagination with additional smaller ones, or several small invaginations exclusively on one side of the cell. Stage -3 cells had evenly distributed small invaginations, and stage -4 cells were smooth spherocytes."

We note that all is "fine" in this description except for absence of the final stages of the RBC transformations, namely the two types of cell death - apoptosis and necrosis. On the basis of our present work, there are two kinds of morphologically similar but physiologically and biochemically different "smooth spherocytes": apoptotic ones (stage +5 ) and necrotic ones (stage -4$)$. From this point of view, echinocytosis is a stage of the apoptotic scenario, and stomacytosis is a stage of the necrotic scenario. By way of illustration we reproduce a pH scale and potential ( $>0$ or $<0$, see Fig. 16), as was suggested by Gedde [34].

\section{Acknowledgements}

This work was partly supported by the BioIndustry Initiative Program of the US Department of State, ISTC grant BII-2629.

\section{References}

[1] S.E. Lux and J. Palek, Disorders of red cell membrane, in: Blood: Principles and Practice of Hematology, R.I. Handin, S.E. Lux and T.P. Stossel, eds, Lippincott, 1995, pp. 1701-1801.

[2] M.F. McMullin, The molecular basis of disorder of the red cell membrane, J. Clin. Pathol. 52 (1999), 245-248.

[3] P.A. Lang, S. Kaiser, S. Myssina, T. Wieder, F. Lang and S.M. Huber, Role of $\mathrm{Ca}^{2+}$-activated $\mathrm{K}^{+}$channels in human erythrocyte apoptosis, Am. J. Physiol. Cell Physiol. 285 (2003), 1553-1560.

[4] K.S. Lang, S. Myssina, V. Brand, C. Sandu, P.A. Lang, S. Berchtold, S.M. Huber, F. Lang and T. Wieder, Involvement of ceramide in hyperosmotic shockinduced death of erythrocytes, Cell Death Differ. 11 (2004), 231-243.

[5] P.A. Lang, D.S. Kempe, S. Myssina, V. Tanneur, C. Birka, S. Laufer, F. Lang, T. Wieder and S.M. Huber, PGE(2) in the regulation of programmed erythrocyte death, Cell Death Differ. 12 (2005), 415-428.

[6] Y. Okada, E. Maeno, T. Shimizu, K. Dezaki, J. Wang and S. Morishima, Receptor-mediated control of regulatory volume decrease (RVD) and apoptotic volume decrease (AVD), J. Physiol. 532 (2001), 3-16.

[7] E.K. Hoffmann and L.O. Simonsen, Membrane mechanisms in volume and $\mathrm{pH}$ regulation in vertebrate cells, Physiol. Rev. 69 (1989), 315-382.

[8] F. Lang, G.L. Busch, M. Ritter, H. Volkl, S. Waldegger, E. Gulbins and D. Haussinger, Functional significance of cell volume regulatory mechanisms, Physiol. Rev. 78 (1998), 247-306.

[9] P. Lipton, Ischemic cell death in brain neurons, Physiol. Rev. 79 (1999), 1431-1568.

[10] E. Maeno, Y. Ishizaki, T. Kanaseki, A. Hazama and Y. Okada, Normotonic cell shrinkage because of disordered volume regulation is an early prerequisite to apoptosis, Proc. Nat. Acad. Sci. USA 97 (2000), 9487-9492.

[11] S.V. Hunt, Separation of lymphocytes and accessory cells, in: Lymphocytes. A Practical Approach, G.G.B. Klaus ed., IRL Press, Oxford, 1987, p. 52.

[12] I.T. Ivanov, Low pH-induced hemolysis of erythrocytes is related to the entry of the acid into cytosole and oxidative stress on cellular membranes, Biochim. Biophys. Acta 1415 (1999), 349-360.

[13] K.S. Lang, P.A. Lang, C. Bauer, C. Duranton, T. Wieder, S.M. Huber and F. Lang, Mechanisms of suicidal erythrocyte death, Cell Physiol. Biochem. 15 (2005), 195-202.

[14] I.V. Mindukshev, I.E. Jahatspanian, N.V. Goncharov, R.O. Jenkins and A.I. Krivchenko, A new method for studying platelets, based upon the low-angle light scattering technique. 1. Theoretical and experimental foundations of the method, Spectroscopy 19 (2005), 235-246.

[15] I.V. Mindukshev, E.E. Ermolaeva, E.V. Vivulanets, E.Yu. Shabanova, N.N. Petrishchev, N.V. Goncharov, R.O. Jenkins and A.I. Krivchenko, A new method for studying platelets, based upon the low-angle light scattering technique. 2. Application of the method in experimental toxicology and clinical pathology, Spectroscopy 19 (2005), 247-257.

[16] I.V. Mindukshev, N.V. Goncharov, E.Yu. Shabanova, E.E. Ermolaeva, M.O. Mironova, A.S. Radilov, R.O. Jenkins and A.I. Krivchenko, A new method for studying platelets, based upon the low-angle light scattering technique. 3. Aggregation hypersensitivity of platelets (ADP agonist) and search for corrective agents, Spectroscopy 20 (2006), 57-66. 
[17] V.P. Zinchenko, V.V. Lee, A.V. Berezhnov, I.V. Mindukshev, R.O. Jenkins and N.V. Goncharov, Application of a low-angle light scattering technique to cell volume and cell signaling studies on Ehrlich ascite tumor cells, Spectroscopy 20 (2006), 45-55.

[18] M. Bessis, Red cell shapes: an illustrated classification and its rationale, in: Red Cell Shape: Physiology, Pathology, Ultrastructure, M. Bessis, R.I. Weed and P.F. Leblond, eds, Springer-Verlag, New York, 1973, pp. 1-23.

[19] I.A. Terskov and I.I. Getelson, [The method of acidic erythrograms], Biofizika 11 (1957), 259-266. [In Russian]

[20] K.S. Lang, C. Duranton, H. Poehlmann, S. Myssina, C. Bauer, F. Lang, T. Wieder and S.M. Huber, Cation channels trigger apoptotic death of erythrocytes, Cell Death Differ. 10 (2003), 249-256.

[21] E. Ponder, Hemolysis and Related Phenomena, Grune \& Stratton, New York, 1948.

[22] H.W.G. Lim, M. Wortis and R. Mukhopadhyay, Stomatocyte-discocyte-echinocyte sequence of the human red blood cell: evidence for the bilayer-couple hypothesis from membrane mechanics, Proc. Natl. Acad. Sci. USA 99 (2002), 1676616769.

[23] J. Garcia-Sancho and V.L. Lew, Detection and separation of human red cells with different calcium contents following uniform calcium permeabilization, J. Physiol. 407 (1988), 505-522.

[24] J.D. Bisognano, J.A. Dix, P.R. Pratap, T.S. Novak and J.C. Freedman, Proton (or hydroxide) fluxes and the biphasic osmotic response of human red blood cells, J. Gen. Physiol. 102 (1993), 99-123.

[25] F.B. Jensen, Red blood cell $\mathrm{pH}$, the Bohr effect, and other oxygenation-linked phenomena in blood $\mathrm{O}_{2}$ and $\mathrm{CO}_{2}$ transport, Acta Physiol. Scand. 182 (2004), 215-227.

[26] R. Motais, H. Guizouarn and F. Garcia-Romeu, Red cell volume regulation: the pivotal role of ionic strength in controlling swelling-dependent transport systems, Biochim. Biophys. Acta 1075 (1991), 169-180.

[27] D.S. Kempe, P.A. Lang, C. Duranton, A. Akel, K.S. Lang, S.M. Huber, T. Wieder and F. Lang, Enhanced programmed cell death of iron-deficient erythrocytes, FASEB J. 20 (2006), 368-370.

[28] R. Nagel and M.H. Steinberg, Hemoglobin SC disease and HbC disorders, in: Disorders of Hemoglobin: Genetics, Pathophysiology and Clinical Management, M.H. Steinberg, B.G. Forget, D.R. Higgs and R.L. Nagel, eds, Cambridge University Press, Cambridge, UK, 2001, pp. 756-785.

[29] D.W. Martin and J. Jesty, Calcium stimulation of procoagulant activity in human erythrocytes: ATP dependence and the effects of modifiers of stimulation and recovery, J. Biol. Chem. 270 (1995), 10468-10474.

[30] Q. Li, V. Jungmann, A. Kiyatkin and P.S. Low, Prostaglandin E2 stimulates a $\mathrm{Ca}^{2+}$-dependent $\mathrm{K}^{+}$channel in human erythrocytes and alters cell volume and filterability, J. Biol. Chem. 271 (1996), 18651-18656.

[31] F. Lang, K.S. Lang, P.A. Lang, S.M. Huber and T. Wieder, Osmotic shock-induced suicidal death of erythrocytes, Acta Physiol. (Oxf.) 187 (2006), 191-198.

[32] M. Bor-Kucukatay, O. Yalcin, O. Gokalp, D. Kipmen-Korgun, A. Yesilkaya, A. Baykal, M. Ispir, U.K. Senturk, I. Kaputlu and O.K. Baskurt, Red blood cell rheological alterations in hypertension induced by chronic inhibition of nitric oxide synthesis in rats, Clin. Hemorheol. 22 (2000), 267-275.

[33] Z.M. May, Z.C. Qu, L. Xia and C.E. Cobb, Nitrite uptake and metabolism and oxidant stress in human erythrocytes, Am. J. Physiol. Cell Physiol. 279 (2000), C1946-C1954.

[34] M.M. Gedde and W.H. Huestis, Membrane potential and red cell shape, Biophys. J. 72 (1997), 1220-1233. 


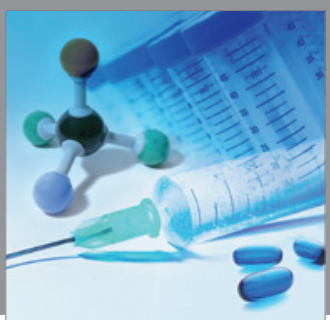

International Journal of

Medicinal Chemistry

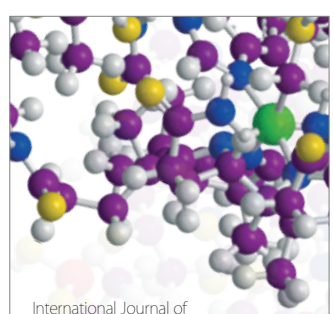

Carbohydrate Chemistry

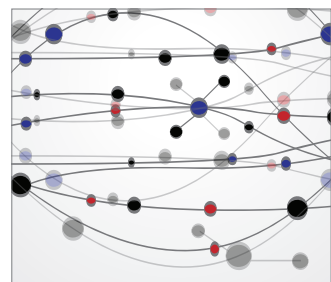

The Scientific World Journal
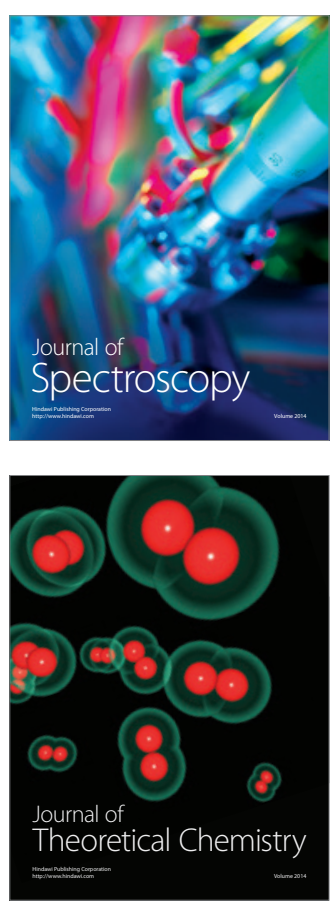
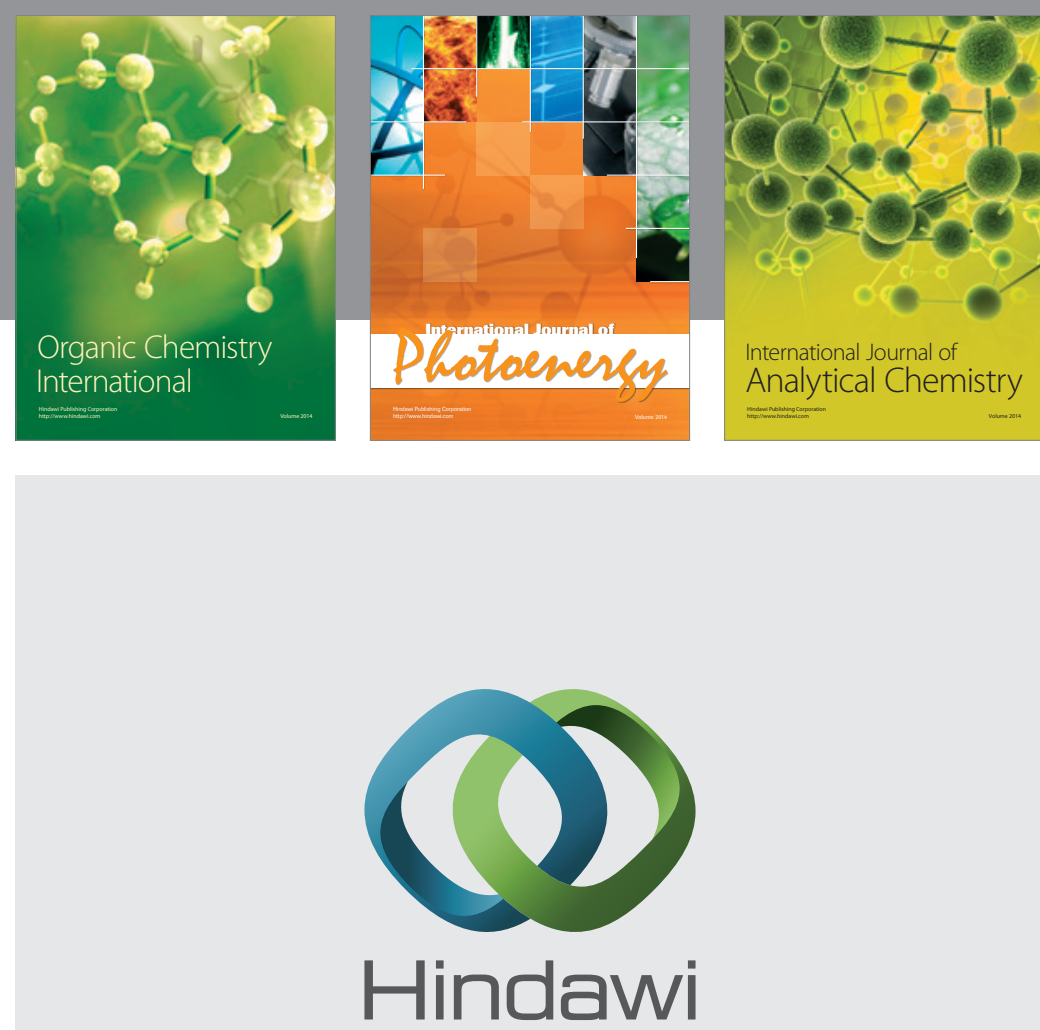

Submit your manuscripts at

http://www.hindawi.com
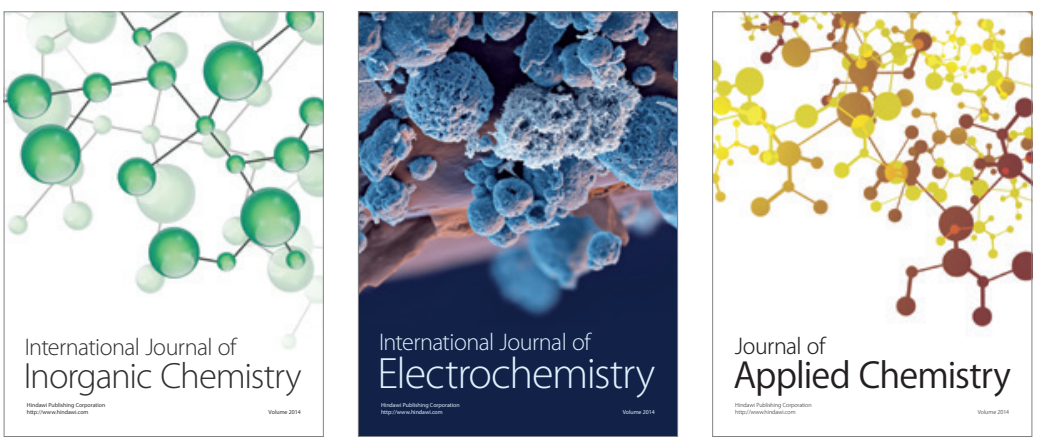

Journal of

Applied Chemistry
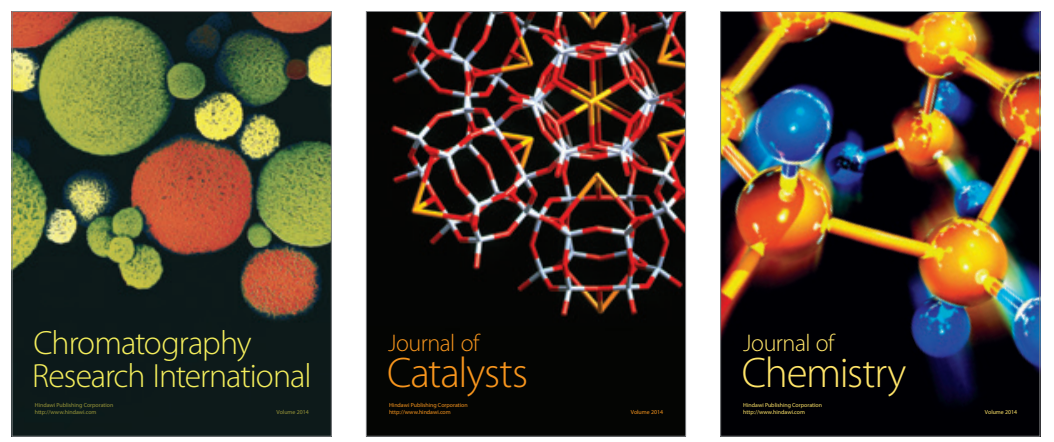
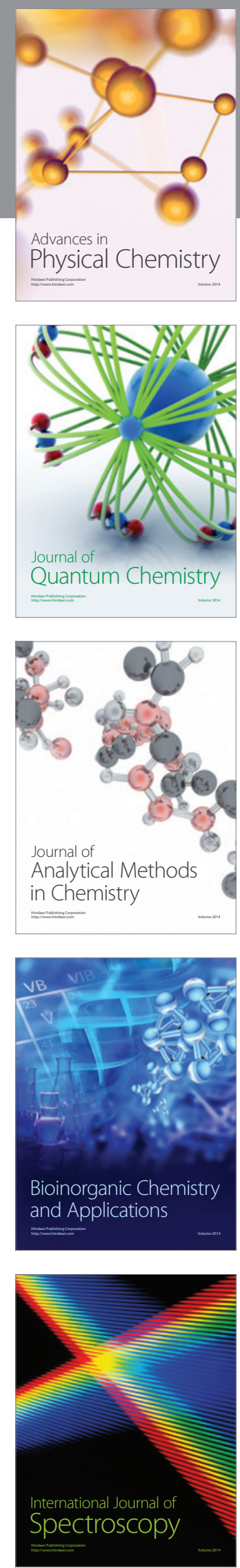